\title{
THE SURFACE ACTIVITY OF PHENOTHIAZINE DERIVATIVES AT THE AIR-SOLUTION INTERFACE*
}

\author{
George Zografi and Ivan Zarenda \\ College of Pharmacy, The University of Michigan, Ann Arbor, Mich., U.S.A.
}

(Received 25 August 1965; accepted 1 November 1965)

\begin{abstract}
The surface activity of trifupromazine, chlorpromazine, promazine, promethazine, and chlorpromazine sulfoxide has been determined at the air-solution interface by the drop-volume method to measure surface tension. Differences in the abilitics of the various phenothiazines employed to affect surface pressure devclopment seem correlated with their relative nonpolarities. Anionic buffer ingredients appear to have an affect on surface activity at $\mathrm{pH} 5 \cdot 0$. Increasing concentrations of phthalate, citrate, and succinate buffers tend to increase surface activity, while increasing the concentration of the acetate buffer has the opposite effect. Raising the $\mathrm{pH}$ greatly increases surface activity of chlorpromazine and its sulfoxide, but the low solubility of the un-ionized form of chlorpromazine prevents it from exhibiting surface activity unless a significant amount of protonated form is also present. The un-ionized form of chlorpromazine sulfoxide is more soluble than chlorpromazine, and it exhibits marked surface activity at high $\mathrm{pH}$.
\end{abstract}

ACCUMULATION at various biological membranes of chlorpromazine and other pharmacologically active phenothiazines has been demonstrated by a number of studies in vitro recently reviewed by Guth and Spirtes. ${ }^{1}$ Guth et al. ${ }^{2}$ have also shown that chlorpromazine acts at rat liver membranes in vivo as well as in vitro. In addition, studies with lipid monomolecular films to simulate the oriented structure of membranes have demonstrated that phenothiazine derivatives ${ }^{3-5}$ and other psychoactive drugs, ${ }^{5}$ in relatively low concentration, accumulate at the monolayer-solution interface.

Whatever receptor surface or membrane may be involved in the action of the phenothiazines, it may be assumed that their widespread activity at membranes is dependent partially on their marked ability to "leave" an aqueous phase for a more nonpolar environment. The tendency of drugs to do this has often been correlated qualitatively with drug action by means of physical chemical measurements such as lipid solubility, $\mathrm{p} K_{\mathrm{a}}$, surface activity, and the ability to interact or complex with other molecules in solution. Measuring the adsorption of drugs at the air-solution interface offers many advantages for studying their escaping tendency from aqueous solution. Surface-tension measurements are extremely sensitive to factors which influence the properties of molecules in solution; ${ }^{6}$ and, since no chemically specific receptors are present, factors governing surface activity will be dependent on the relationship between solvent and drug. Thus, although the air-solution interface does not approach

* The work was supported by Research Grant GM 12886-01, from the National Institutes of Health, Bethesda, Md. 
a true receptor surface, its simplicity (air) and the sensitivity of surface-tension measurements make it a valuable tool.

Two studies have been reported involving phenothiazines at the air-solution interface. ${ }^{7,8}$ Both have demonstrated the surface activity of these compounds, but also have tended to oversimplify the picture. Villalonga et al. ${ }^{7}$ have measured the ability of four phenothiazines to lower the surface tension of an air $-0.1 \mathrm{~N} \mathrm{HCl}$ solution. They used the Gibbs equation to calculate the number of molecules adsorbed per unit area for various drug concentrations. Maximal adsorption at high concentrations was converted to area per molecule by taking reciprocals, and this was related to the geometry of molecular models. The differences in area obtained for promethazine (46 $\AA^{2}$ ) and promazine $\left(66 \AA^{2}\right.$ ) have been postulated as reasons for differing pharmacological action. ${ }^{9}$ In general, however, areas obtained from such data do not approach the true dimensions of molecules at an interface. Rather, they are larger and subject to change by such factors as electrolyte concentration, $\mathrm{pH}$, and mixed film formation. The region in which the area per molecule becomes independent of increasing concentration has been termed ${ }^{10}$ the region of saturation adsorption. It is suggested that this commences somewhat before the critical micelle concentration due to a hydration layer around the polar group which prevents further reduction in area with increasing surface pressure. lonic repulsion due to ionized polar groups may also contribute. Thus it is not surprising that these areas are subject to change by conditions in solution.

Seeman and Bialy ${ }^{8}$ have measured the surface tension of psychoactive drug solutions at $\mathrm{pH} 7 \cdot 0$. Despite different chemical structures and $\mathrm{p} K_{\mathrm{a}}$ values, all drugs exhibited the same saturation adsorption area of about $87 \AA^{2}$. The constancy of the value, and the fact that it is larger than that reported at the lower $\mathrm{pH}^{7}$ where adsorption is less, is surprising. In addition, preliminary results in this laboratory ${ }^{3}$ at about the same $\mathrm{pH}$ indicate that concentrations required for surface activity are higher than those reported by Seeman and Bialy. This is apparent also from the results with sodium lauryl sulfate obtained by Roe and Brass.11

In view of some of these questions and in order to probe more deeply into the problem, a study concerned with adsorption of phenothiazines at the air-solution interface was initiated.

\section{EXPERIMENTAL}

\section{Materials}

Chlorpromazine $\mathrm{HCl}$ [2-chloro-10-(3-dimethylaminopropyl)phenothiazine] and its sulfoxide were generously supplied by Smith, Kline and French Laboratories, Philadelphia, $\mathrm{Pa}$; triflupromazine $\mathrm{HCl}$ [2-trifluomethyl-10-(3-dimethylaminopropyl)phenothiazine] was generously supplied by the Squibb Co., New Brunswick, N.J.; and promazine $\mathrm{HCl}$ [10-(3-dimethylaminopropyl)phenothiazine] and promethazine $\mathrm{HCl}$ [10-(2-dimethylamino-2-methylethyl)phenothiazine] were generously supplied by Wyeth Laboratories, Philadelphia, Pa. These are designated in this study as $\mathrm{CPZ}$, CPZ-O, TPZ, PZ, and PMZ, respectively. All were recrystallized from isopropyl alcohol with the exception of CPZ-O. All buffer ingredients and inorganic compounds were of reagent grade, and the water used was prepared by double distillation from alkaline permanganate solution. 


\section{Surface-tension measurments}

The drop-volume method ${ }^{12}$ was used for all surface-tension measurements. All drop volumes were independent of time, and thus the values of surface tension are equilibrium values. Preliminary studies showed no significant difference with the Wilhelmy plate method used previously, ${ }^{3}$ but the drop-volume method allowed for smaller solution volumes and less contact with the environment. This helped to eliminate possible drug decomposition. All studies were conducted at $25^{\circ} \pm 0 \cdot 1^{\circ}$. The drop volume apparatus* was essentially the same as that previously described ${ }^{13}$ except for an inlet tube which allowed nitrogen to be introduced when necessary. The syringe tip was made of stainless steel and had a radius of $0.2967 \mathrm{~cm}$. Details for calculating surface tension and for the experimental procedure have been described earlier. ${ }^{13}$ Since $\mathrm{pH}$ was maintained constant in all studies and excess counter-ions were present, the appropriate form of the Gibbs equation ${ }^{14}$ was used to calculate the number of molecules adsorbed per unit area and, hence, the area per molecule.

Measurements of surface pressure (surface tension of solvent minus surface tension of solution) were made under a variety of conditions. Studies were first conducted at pH 2.0 where all the drugs are in the hydrochloride salt form. A $0.01 \mathrm{M} \mathrm{HCl}, 0.09 \mathrm{M}$ $\mathrm{NaCl}$ solution was used as the solvent. Next, the possible effect that anionic buffer components might exert on surface activity, and the possible interfacial interaction of drug and buffer were considered. For this purpose surface pressures were measured in phthalate, citrate, succinate, and acetate buffers-all at $\mathrm{pH} 5.0$ and ionic strength $0 \cdot 1$. Sodium chloride was used to adjust ionic strength in all cases. In order to observe the effect of the un-ionized species, measurements were made with $\mathrm{CPZ}$ at $\mathrm{pH} 7.2$ in Tris and phosphate buffers $(0.01 \mathrm{M})$; at $\mathrm{pH} 9.0$ in a Tris buffer $(0.01 \mathrm{M})$; and at pH $10 \cdot 6,11 \cdot 4$, and $12 \cdot 0$ in $\mathrm{NaOH}$ solutions. $\mathrm{CPZ}-\mathrm{O}$ at $\mathrm{pH} 12 \cdot 0$ was also considered. All the drugs used in this study have reported $\mathrm{p} K_{\mathrm{a}}$ values of $9 \cdot 0$ or greater. ${ }^{15,16}$

\section{RESULTS}

\section{Studies at $\mathrm{pH} 2 \cdot 0$}

Curves depicting the surface pressure change with the logarithm of molar concentration at $\mathrm{pH} 2 \cdot 0$ are given in Fig. 1. A comparison of initial surface pressure changes indicates that TPZ is much more surface active than the other compounds. At the other extreme, little surface activity is observed for CPZ-O, although significant surface pressure development commences at concentrations approaching $0 \cdot 1 \mathrm{M}$. $\mathrm{CPZ}, \mathrm{PZ}$, and PMZ begin to develop surface pressure in the same region of concentration, but subsequent changes are greater for CPZ. Values of area per molecule in square Ångstroms at saturation adsorption are $66 \cdot 3,69 \cdot 5,65 \cdot 5$, and $77 \cdot 0$ for CPZ, TPZ, PZ, and PMZ respectively. The values for $P Z$ agree quite well with those of Villalonga et al.; 7 however, those for promethazine are quite different. Since one would expect less adsorption, and hence a higher area per molecule for a branch-chain isomer, the increase in area observed for promethazine in this study seems reasonable.

\section{The effect of buffers at $p H 5 \cdot 0$}

Surface-pressure measurements for $\mathrm{CPZ}$ in the various buffer solutions at $\mathrm{pH} 5 \cdot 0$ are given in Fig. 2 along with the curves obtained at $\mathrm{pH} 2.0$ and 7.2. It is interesting

\footnotetext{
* Frater Instrument Co., Corona, N.Y.
} 


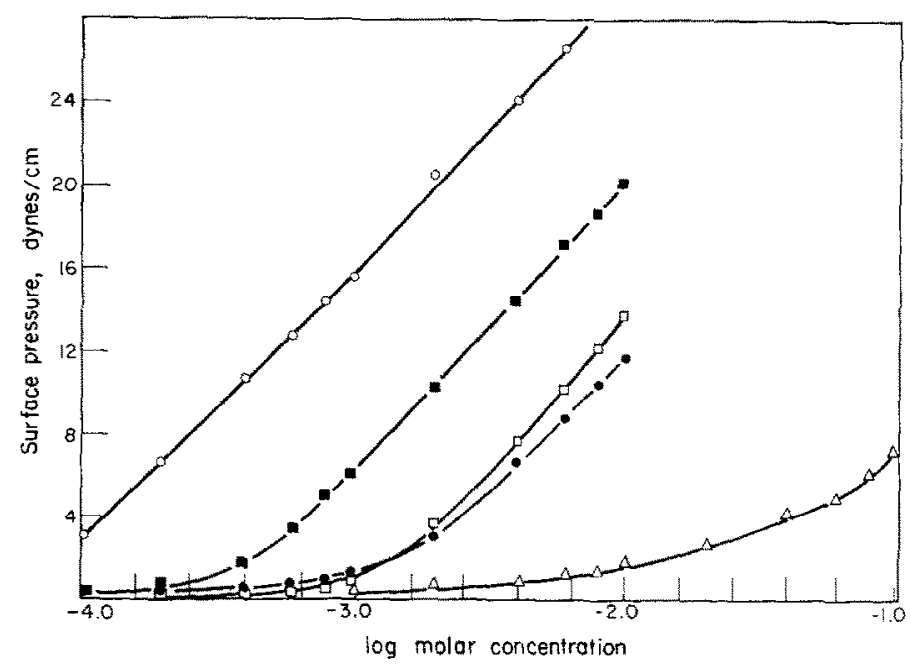

FIG. 1. Surface pressure $(\pi)$ vs. log molar concentration of various drugs at $\mathrm{pH} 2 \cdot 0$, ionic strength $0-1$ and $25^{\circ}$. Key: TPZ $(O) ; \mathrm{CPZ}(\mathbb{G}) ; \mathrm{PZ}(\square) ; \operatorname{PMZ}(\bullet) ; \mathrm{CPZ}-0(\triangle)$.

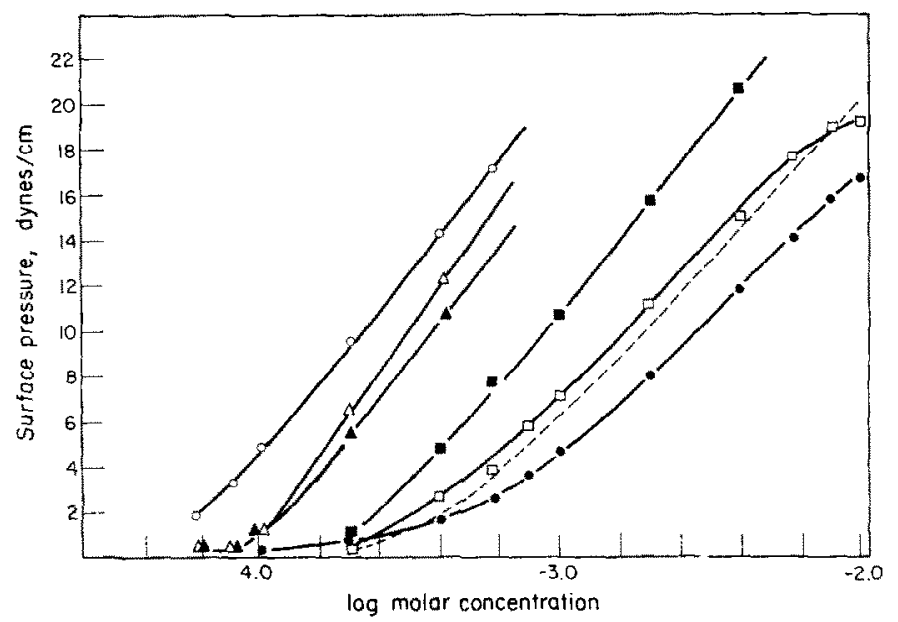

Frg. 2. Surface pressure ( $\pi$ ) vs. $\log$ molar concentration of $\mathrm{CPZ}$, ionic strength $0.1,25^{\circ}$, and in various buffers. Key: $\mathrm{pH} 5 \cdot 0,0.073 \mathrm{M}$ phthalate $(\mathrm{O}) ; \mathrm{pH} 5 \cdot 0,0.025 \mathrm{M}$ citrate $(\square) ; \mathrm{pH} 5.0,0.10 \mathrm{M}$ succinate $(\square) ; \mathrm{pH} 5.0,0.10 \mathrm{M}$ acetate $(\bullet) ; \mathrm{pH} 7.2,0.01 \mathrm{M}$ Tris $(\boldsymbol{\Delta}) ; \mathrm{pH} 7.2,0.01 \mathrm{M}$ phosphate $(\Delta)$. Dotted line depicts data for $\mathrm{CPZ}$ at $\mathrm{pH} 20$.

to note the increase in surface activity, as compared to $\mathrm{pH} 2 \cdot 0$, due to the phthalate, citrate, and succinate buffers and the decrease due to the acetate buffer. The same effects were noted for all drugs, the extent of change being greatest for TPZ, the most surface-active drug, and least for PMZ, the least surface-active drug. The buffer solutions alone exhibited no measurable surface activity. Dilution of each buffer with readjustment to an ionic strength of 0.1 in $\mathrm{NaCl}$, influences surface activity. Significant decreases in surface pressure were noted by diluting the phthalate, citrate, and succinate buffers, while increases in surface pressure were noted when the acetate was diluted. 


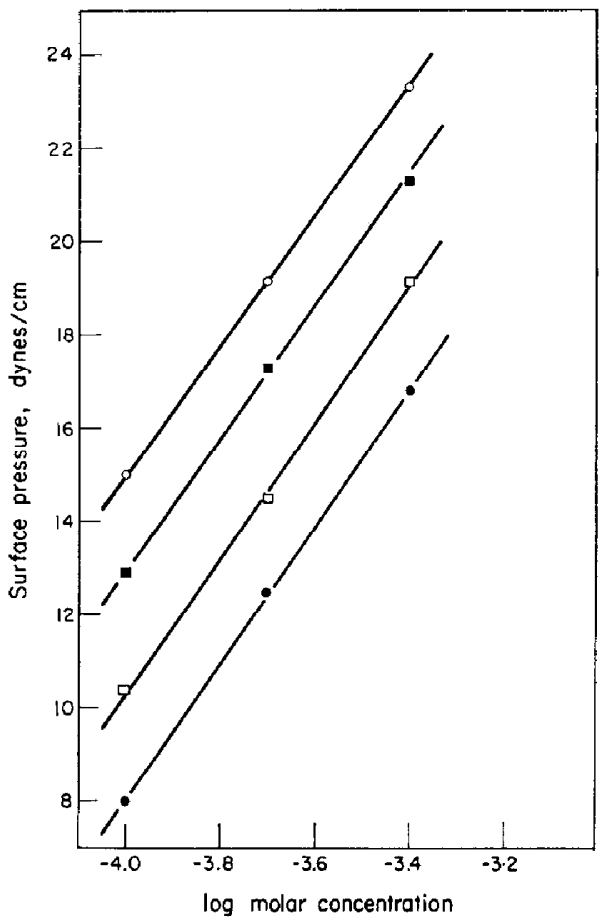

FIG. 3. Surface pressure ( $\pi$ ) vs. $\log$ molar concentration of TPZ in various concentrations of phthalate buffer at $\mathrm{pH} 5.0$, ionic strength 0.1 and $25^{\circ}$. Key: 0.073 M (O); $0.036 \mathrm{M}(\mathbf{G}) ; 0.015 \mathrm{M}(\square)$; $0.007 \mathrm{M}(\bullet)$.

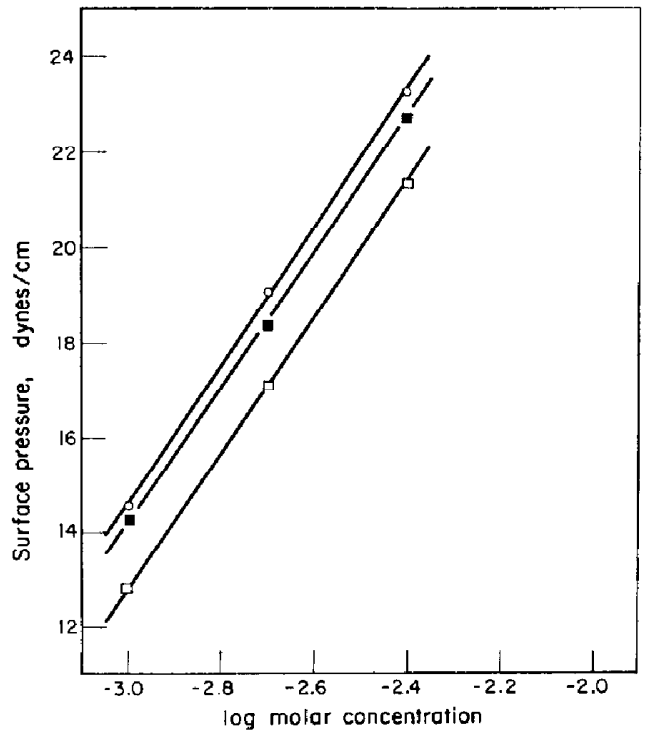

FIG. 4. Surface pressure ( $\pi$ ) vs. $\log$ molar concentration of TPZ in various concentrations of acetate buffer at pH 5.0, ionic strength 0.1 and $25^{\circ}$. Key: $0.025 \mathrm{M}(\mathrm{O}) ; 0.05 \mathrm{M}(\mathrm{O}) ; 0.10 \mathrm{M}([\mathrm{J})$. B.P. $-2 \mathrm{R}$ 
The phthalate and citrate buffers seem to have a greater effect upon dilution than have the succinate and acetate buffers. Figures 3 and 4 indicate the effect of phthalate and acetate, respectively, on TPZ, the drug showing the greatest change upon dilution.

\section{The effect of the un-ionized speries}

In Fig. 2 the surface activity of $\mathrm{CPZ}$ at $\mathrm{pH} 7.2$ in Tris and phosphate buffers is depicted. It may be noted that the concentration range required for surface pressure development is much lower than at $\mathrm{pH} 2 \cdot 0$, and that the change in surface pressure with concentration is greater. This is reflected in a saturation adsorption area of $51 \AA^{2}$ and $55 \AA^{2}$ in phosphate and Tris buffers respectively. These differ from the value of about $87 \AA^{2}$ given by Seeman and Bialy ${ }^{8}$ under similar conditions; however, the

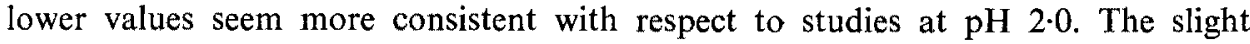
difference in data obtained for Tris and phosphate buffers appears to reflect a buffer effect similar to that seen at $\mathrm{pH} 5 \cdot 0$. It is interesting to note that $\mathrm{CPZ}$ in phthalate buffer, although seemingly completely ionized, exhibits surface pressures at lower concentrations than at $\mathrm{pH} 7 \cdot 2$.

Since the degree of ionization for $\mathrm{CPZ}$ and, consequently, its solubility, are reduced markedly at $\mathrm{pH}$ values of 9.0 and higher, the unusual behavior observed in this $\mathrm{pH}$ region might be expected. For example, if the solution was prepared with the free base of $\mathrm{CPZ}$, rather than the hydrochloride salt, no surface activity was noted up to the solubility limit $\left(6 \times 10^{-6} \mathrm{M}\right.$ at pH 9.0 and $2.4 \times 10^{-6} \mathrm{M}$ at $\left.\mathrm{pH} 12.0\right)$. However, if the hydrochloride form was used, higher solubilities were noted $\left(3 \times 10^{-5} \mathrm{M}\right.$ at $\mathrm{pH} 9 \cdot 0$ ). Surface pressures up to 4 dynes $/ \mathrm{cm}$ were noted in this case, but only at the supersaturated levels. Lack of wetting along the sides of the glass container at these higher concentrations was also observed, probably owing to adsorption on the glass. It appears that an oil is produced when the hydrochloride is converted to the free base in situ, and that this oil is more water soluble. CPZ-O, which is more soluble than CPZ in the free base form, developed surface pressures of $4.5,12.6$, and 15.9 dynes/cm for concentrations of $1 \times 10^{-4} \mathrm{M}, 4 \times 10^{-4} \mathrm{M}$, and $8 \times 10^{-4} \mathrm{M}$ respectively. No adsorption on the glass containers was noted.

\section{DISCUSSION}

It is apparent from these studies that the phenothiazine derivatives considered have a strong tendency to leave an aqucous environment for one which is more nonpolar. This is most striking when one compares surface properties of the phenothiazines with some of the local anesthetics studied by Skou. ${ }^{17}$ For instance, the concentration required to produce a 5 dyne $/ \mathrm{cm}$ surface pressure at $\mathrm{pH} 3.5$ for Nupercaine, the most active molecule studied, is about $6 \times 10^{-3} \mathrm{M}$; while at $\mathrm{pH}$ $2.0,8 \times 10^{-4} \mathrm{M} \mathrm{CPZ}$ and $1 \times 10^{-4} \mathrm{M} \mathrm{TPZ}$ have the same effect. Even at pH $11 \cdot 0$ completely un-ionized procaine has less surface activity than the un-ionized form of CPZ-O.

By comparing the results of studies at $\mathrm{pH} 2 \cdot 0$, one can observe the marked effect substitution on the phenothiazine ring has on this "escaping tendency". If the phenothiazine ring is considered the nonpolar portion of the molecule, one would expect such a critical dependence on different substituent groups. For instance, the addition of one $-\mathrm{CH}_{2}-$ group to the alkyl chain of a surface-active agent reduces the con- 
centration necessary to obtain the same surface pressure by about one third. ${ }^{18}$ The contribution of the more nonpolar $-\mathrm{CF}_{3}-$ group, as in TPZ, would be expected to be greater, as seen in this study. The constancy of the saturation adsorption areas for TPZ, CPZ, and PZ at $\mathrm{pH} 2 \cdot \mathbf{0}$, as compared to a greater value for PMZ, would be expected also if the 3-dimethylaminopropyl moiety is considered the polar portion of TPZ, CPZ, and PZ, since Vader ${ }^{10}$ has shown that the polar group is primarily responsible for these areas. Thus we see that substitution on different parts of these molecules appears to have significant yet different effects on their surface activity. Changes in the nonpolar group influence the concentration required for surface activity, while changes in the polar portion influence the maximal amount of adsorption. The former effect may be considered analogous to drug affinity as discussed by Ariëns and Simonis, ${ }^{19}$ while the latter may be considered analogous to the intrinsic activity of drugs.

The marked effect of buffer ingredients is difficult to ascertain quantitatively because it was impossible to obtain the same concentration of each buffer species and still maintain $\mathrm{pH}$ and ionic strength constant. Ilowever, these results are interesting since they indicate the sensitivity of the adsorption process to environmental factors normally not considered. For instance, the fact that a solution is buffered to $\mathrm{pH} 5 \cdot 0$ in bulk solution does not mean that the surface $\mathrm{pH}$ is 5.0 . The surface concentration of the buffer ingredients may be greatly altered, owing to selective adsorption of one species over another, electrical repulsion and attraction of ions, and interaction of drug and buffer anions. Some evidence for interaction was noted by the observation that the solubility of the drugs is much less in the presence of the phthalate buffer than at $\mathrm{pH} 2 \cdot 0$. For example TPZ has a solubility of $7 \times 10^{-4} \mathrm{M}$ in $0.07 \mathrm{M}$ buffer, while that of $\mathrm{PZ}$ is about $3.5 \times 10^{-3} \mathrm{M}$. Dilution of the buffer to $0.015 \mathrm{M}$ gives a solubility of $2.4 \times 10^{-3} \mathrm{M}$ for TPZ and more than $1 \times 10^{-1} \mathrm{M}$ for PZ. This latter result correlates well with the fact that the diluted buffer had practically no effect on $\mathrm{PZ}$ surface activity when compared to the effect at $\mathrm{pH} 2 \cdot 0$. Although it was impossible to isolate and identify a pure compound, an oil was produced, indicating some type of bulk interaction. Phase solubility analysis indicated that two species may be present, possibly the mono- and di-substituted phthalates. Unfortunately, the solubility of the drugs in the presence of the other buffers is quite high, and, in addition, spectral methods indicate no interactions. However, this does not preclude the possibility of surface complexation which could occur at these lower concentrations. The reverse effect of the acetate buffer is interesting and may be related to the influence of acetate ion on the structure of water. ${ }^{20}$ Studies concerned with possible surface complexation and factors influencing water structure are now underway.

Whatever the mechanism of buffer effect may be, it is clear that any study comparing the action of these drugs in vitro must consider the influence of buffers and other species in solution. It is quite possible that these results may be of some importance in understanding the pharmacological action of these drugs. The ability to interact so readily with anionic species to form ion-pairs could play a role in the transport to and accumulation at membranes and other receptor surfaces. It is also apparent from these studies that differences between ionized and un-ionized phenothiazine molecules have little meaning if the ionized species combines with other molecules so readily, and if the un-ionized species is no insoluble that significant concentrations are not attainable. 
Acknowledgements-The authors wish to thank Mrs. Nell G. Wu for carrying out the solubility measurements and Dr. William I. Higuchi for helpful discussions.

\section{REFERENCES}

1. P. S. GutH and M. A. SPIRTES, Int. Rev. Neurobiol. 7, 231 (1964).

2. P. S. Guth, J. Amaro, O. Z. Sellinger and L. Elmer, Biochem. Phurmac. 14, 769 (1965).

3. G. Zografi, D. E. Auslander and P. E. Lytell, J. pharm. Sci. 53, 573 (1964).

4. G. Zografi and D. E. Auslander, J. pharm. Sci. 54, 1313 (1965).

5. L. L. M. Van Deenen and R. A. Demel, Biochim. biophys. Acta 94, 314 (1964).

6. A. P. Brady and A. G. Brown, Monomolecular Layers Symposium, H. SobotkA, Ed., p. 33. Amer. Assoc. for the Advancement of Science (1951).

7. F. Villalonga, E. Fried and J. A. IzQuierdo, Archs int. pharmacodyn. 130, 260 (1961).

8. P. M. Seeman and H. S. Bialy, Biochem. Pharmac. 12, 1181 (1963).

9. B. M. Bloom and G. D. Laubach, Ann. Rev. Pharmac. 2, 69 (1962).

10. F. v.V. VADER, Trans. Faraday Soc. 56, 1067 (1960).

11. C. P. Roe and P. D. BraSs, J. Am. chem. Soc. 76, 4703 (1954).

12. W. Harkins and F. Brown, J. Am. chem. Soc. 16, 499 (1919).

13. N. D. Weiner and G. Zografi, J. pharm. Sci. 54, 436 (1965).

14. J. T. Davies and E. K. Rideal, Interfacial Phenomena, 2nd ed., p. 198. Academic Press, New York (1963).

15. P. B. Marshall, Br. J. Pharmac. 10, 270 (1955).

16. L. G. Chatten and L. E. Harris, Analyt. Chem. 34, 1495 (1962).

17. J. C. Skou, Acta pharmac. (Kbh.) 10, 305 (1954).

18. J. T. Davies and E. K. Rideal, Interfacial Phenomena. Op. cit., p. 155.

19. E. J. ARIËNS and A. M. Simonis, J. Pharm. Pharmac. 16, 137 (1964).

20. J. L. Kavanau, Structure and Function in Biological Membranes, Vol. 1, p. 228. Holden-Day, San Francisco (1965). 